\title{
Horizon, Objectivity and Reality in the Physical Sciences
}

Patrick A. Heelan

Georgetown University, heelanp@georgetown.edu

Follow this and additional works at: https://fordham.bepress.com/phil_research

Part of the Continental Philosophy Commons, and the Philosophy of Science Commons

\section{Recommended Citation}

Heelan, Patrick A., "Horizon, Objectivity and Reality in the Physical Sciences" (1967). Research Resources. 3. https://fordham.bepress.com/phil_research/3

This Article is brought to you for free and open access by the Hermeneutic and Phenomenological Philosophies of Science at DigitalResearch@Fordham. It has been accepted for inclusion in Research Resources by an authorized administrator of DigitalResearch@Fordham. For more information, please contact considine@fordham.edu. 
Horizon, Objectivity and Reality in the Physical Sciences ${ }^{1}$

\author{
Patrick A. Heelan
}

\title{
INTRODUCTION: THE PHENOMENOLOGICAL STYLE
}

Of the two contemporary styles of philosophizing, logical empiricism has taken a very positive attitude towards natural science, seeing in it the type of perfect human knowledge, while phenomenology has taken a negative attitude towards accusing it of substituting for the objects of natural experience abstract mathematical models alien to truth. If the great weakness of logical empiricism, for phenomenological thinkers, is its systematic neglect of intuition and insight, the great defect of phenomenology is, for those of the other school, its tendency to substitute the mystery of subjective intuitions for the clarity of public discourse linked to the objective methods of empirical science.

Although it is generally the case that philosophy pursued in a phenomenological style is characterized by dialectical, often polemical, criticism of the mathematical methods of natural science and especially of the cult of "scientific objectivity," this does not imply that legitimate scientific activity cannot today be redeemed from its original sin by a proper phenomenological analysis, where the original sin of science [376] is Cartesian rationalism. In what sense then is Cartesian rationalism original to science? Phenomenology would have it that without this continuing association with Cartesian rationalism science could not cont nue. If this is the case, then there is no way in which science can be redeemed and its presence in our culture must be counteracted by a sustained polemic in which science plays the role of a dialectical antithesis If, however, as the present author believes, Cartesian rationalism was only historically linked with science, then a proper phenomenological analysis will be able to show man's scientific activity to be part of a fuller humanistic activity in which man's alienation from the world of science can be overcome.

The author wishes to explore the utility of a phenomenological style of philosophizing about nature called the analysis of horizons. The name refers to a banner of philosophical reflection practiced by many philosophers mostly of European origin who have been influenced by the Husserlian tradition, like Heidegger, de Waelhens, Gurwitsch, Merleau-Ponty, Luijpen--to mention but a 
few. The author is convinced, however, that contemporary phenomenology cannot contribute much of value to the philosophy of science unless enlarged in some such as the author outlines below.

To philosophize about science in a phenomenological vein, one must begin with a phenomenological description of the form of life of scientific research, because it is only within a form of life, that is, within a $\mathrm{wa}^{\mathrm{y}}$ of experiencing objects, that objects present themselves as real. Mathematical signs, diagrams, tables, symbolic calculi, however useful they may be within a scientific form of life, do not of themselves present us the real object of scientific research in so far as this is envisioned as research into nature. Not however that one can retain a scientific way of experiencing nature and lay these tools of science aside for without them we would have no way of understanding the 'language' of dials, counters or scintillations which 'speak' to us about what is the case within the scientific experimental context. A scientific form of life is then a way of experiencing objects [377] within the context of doing experimental science, that is, within the empirical context in which we live amidst real scientific states of affairs.

A phenomenological description of a scientific form of life is one made from a standpoint inside human consciousness. It tries to reach the meaning structure or the intentionality structure of that form of life as a mode of lived conscious awareness of scientific objects and scientific states of affairs. Human consciousness is never simply a self-consciousness, a mere cogito. It is essentially a cogito cogitatum, that is, a subject open to an environing World of objects given or to be given in experience. The classic structure of human consciousness is, then, a polarity between a subject and a field of objects towards which it is turned intentionally. The objects which terminate the intention of the subject are of course objects within consciousness (such is the meaning of the term ' object'). The study of intentionality (or noetic-noematic structures) then becomes in phenomenology the study of the way objects are constituted as objects present to and in consciousness by the functioning of the appropriate intention which characterizes the form of life in question (when this is viewed from inside consciousness as a meaning-bearing activity). The notion of a constituting intention, then, is central to phenomenological analysis. In its original Aristotelian sense, intentionality meant the referential character of knowledge. With Husserl, however, 'intention' or 'constitution' took on a more complex meaning eventually embracing the following elements: (a) the objectification of sensory (hyletic) data by unifying them into an empirical object and relating the object so established to one thing; (b) the relating of successive sensory data to a permanent object; (c) the conjoining to an object of the various profiles (Abschattungen) which it would present under other circumstances; (d) the projection of the object into an 
intersubjective field. ${ }^{3}$ Various aspects of 'Constitution' will be discussed below under the heading 'objectivity.'

Before attempting to perform a phenomenological analysis of scientific activity, some comments of a methodological character seem to be required. In the first place, it is not transparently clear at the start of an investigation of this sort what it is 'to do science.' We do [378] know roughly however which activities are to be called 'scientific activities' and which not--sufficiently at least for the purposes of this investigation. Learning science is in many respects like learning to play golf. It is an apprenticeship to a tradition possessed by a community of (more or less) expert practitioners. Science is not developed in isolation from a community and a tradition. The community and the tradition, however, are no more likely to be able to give a satisfactory reflective account of what they do than a good golfer is likely to be able to give a satisfactory reflective account of what it is to play golf. Normal science, to use Kuhn's terms, is accustomed to function by 'paradigms. ${ }^{4}$ These are what the apprentice scientist learns. They comprise, for example, typical experiments, a theory-of-L, perhaps a theory-for-L, perhaps even some meta-scientific rules, but principally they are a form of life (L) which is not entirely transparently rational even to those who practice it best. A descriptive phenomenology of a scientific form of life will then he difficult to obtain, and especially so if the philosopher himself has not been apprenticed to a scientific tradition. Moreover, much of what scientists themselves say when they attempt to formulate the nature of scientific experience is mixed with theoretical interpretative elements of a philosophical hind foreign to pure phenomenological description. While theoretical interpretative elements cannot be wholly eliminated, only those should be admitted which express the intuitions on which a pure phenomenological description is based.

The pure phenomenological description of a scientific form of life explicitates the intentionality structure latent in that form of life. To achieve this, it is necessary to seek an intuition or insight into the physical and intentional structure of the scientific way of experiencing nature. A note of caution has to be introduced, for, even in such a reflective search in matters which for a large part are interior to consciousness, one is not assured by the fact of insight that true knowledge and still less that true and apodictic knowledge has been achieved. The fact of insight or intuition does not justify the formalizations or judgments in which it subsequently results and in which alone propositional truth or falsity are to be found. Insight has to be followed by the effort to formulate the content of the insight in propositions, laws and theories. Formulations are in the public domain, but insights or intuitions are not. These formulations have then to be tested in the public domain by a community of scholars. A well-tested and accepted [379] account elucidates for the community of scholars who have shared 
this common work the structure of the intentionality embodied in the scientific activity in question. A scientifc intentionality structure is like a vector pointing out certain objects (the noemata). Only when the direction of the vector is known does it become possible to define the nature of the objects towards which the vector points. It is the aim of this paper to investigate the vector of inquiry associated with the physical sciences. With this in view, we introduce the technical notions of horizon, noetic-noematie structure, objectivity, World and reality.

\section{ANALYSIS OF HORIZONS}

The attempt to elucidate and criticize the kind of cognitive interntionalitystructure implicit (and sometimes-but rarely-explicit) in the form of life which characterizes a given type of empirical scientific investigation, is called an analysis of the horizon of the science. An intentionality-structure is composed of two aspects correlative to one another-a noetic (or subjective) aspect and a noematic (or objective) aspect. ${ }^{5}$ The noetic aspect is the subjective heuristic anticipation as already structured by the method of inquiry through which the object (or noema) which fulfills the anticipation is to be attained. The noema or object here and now manifesting itself to a knowing subject is revealed, in the light of the heuristic anticipation to which it corresponds. A [380] noema is an object of concrete factual knowledge. Noesis and noema are then the two correlative poles, subjective and objective, which taken together comprise every intentionality-structure. As Dondeyne puts it:

Consciousness is intentional; ... it presents the form of a dialectical relation between a ' 'noesis' and a 'noema,' the two calling to each other and constituting one another in an indissoluble unity.... [Moreover] an intention to be actualized, must be incarnated in a behavior 'sui generis' called 'observation'. . .

Noesis is a structured heuristic anticipation. It corresponds to an open field of connected (but generally implicit) questions addressed by a subject to empirical experience and implying the acceptance of a particular interpretation of experience, whether in a common sense framework or in a scientific framework. The domain of reality to which this particular interpretation of experience belongs is a horizon. A horizon, then, is the set of actual or possible objects revealed or to be revealed by the functioning of a particular empirical noetic intention. A functioning noetic intention then constitutes a reality-outline to be filled. The filling of that outline does not occur all at once, but is a progressive process. Although a functioning noetic intention is the invariant in the structuring of a horizon, a horizon is not a static ensemble of noemata given once and for all. It is an organically growing system resulting from the progressive exploration of the 
horizon by a community of subjects. The intentionality-structure of a particular question, then, prefigures the kind of answer it will receive. It does not determine, however, that there should be a meaningful answer, but only that an answer, if a meaningful one should be given, will appear of as totally disconnected with previous experience, but as revealing some looked-for noema within an already ordered context of noemata which we called 'a horizon.'

The World is the totality of all horizons. It is the "horizon of all horizons." 7 True reality for a subject is his World. It constitutes [380] the ultimate horizon in which particular events have a place if and only if they are real. A noema has the character of reality only in so far as it partakes in the reality of a total ordered context of actual and possible objects which is the World. The World, then, is the source of meaning of the term 'real. ' 8 Reality (optic reality) then can be defined as. something which makes its appearance directly or indirectly as one of the objects in the World. In order to specify further the meaning of the word 'real,' it is necessary to distinguish different classes of objects and different types of objectivity.

\section{OBJECTIVITY}

Objectivity is the character of being an object of human conscious awareness. ${ }^{9}$ In the cognitive realm an object is what is known by an act of knowing in so far as it is known. ${ }^{10}$ It is sufficient for our purpose [382] that we distinguish three different (but not mutually exclusive) types of objectivity, each founded upon a different kind of subject-object relation: (i) empirical objectivity, (ii) public objectivity, and (iii) strict objectivity.11

Empirical objectivity is that founded upon the relation of intended spatial exteriority between an object given in perception and the point of perspective from which the knowing subject surveys the spatial field. For example, a given (external) sensed object makes its appearance somewhere in the spatial field of a sensing subject but, qua external, it occurs at some place separated from that place which constitutes the extrapolated (or intrapolated 1) subjective pole of the outwardlooking "extroverted" self. The noetic attitude of extroversion is that which manifests (or constitutes as known) the exteriority of the empirical object to the perceiving subject.

Extroversion is the primitive intention or orientation of our everyday selves when we move or act intelligently but in a biological pattern, grasping what Lonergan calls the `already out there now real. '12 Is this primitive intention we called extroversion no more than the passive reflection of an already spatially ordered totality (spatially ordered, that is, in a sense that is independent of the subject's activity in the World and affirmed precisely in that sense), a glimpse of what is independently of the presence and activity of the subject and insofar as it 
is independent of the presence and activity of the subject? Or is extroversion the active anticipation, based upon the complex sensory and motor activities of man, of certain kinds of objects to be met, touched, used, consumed, desired or feared in his commerce with the World? In the former case, the subject does not contribute by his own activity to the constitution of the empirical object as suchhe merely recognizes it out-there-now; in the latter case, the subject does. In either case, the subject-object relation is an intended spatial one-one, that is, of spatial separation-though as we have seen there are two views (at least 1) as to how spatial relations are constituted as [382] that we distinguish three different (but not mutually exclusive) types of objectivity, each founded upon a different kind of subject-object relation: (i) empirical objectivity, (ii) public objectivity, and (iii) strict objectivity. ${ }^{11}$

Empirical objectivity is that founded upon the relation of intended spatial exteriority between an object given in perception and the point of perspective from which the knowing subject surveys the spatial field. For example, a given (external) sensed object makes its appearance somewhere in the spatial field of a sensing subject but, qua external, it occurs at some place separated from that place which constitutes the extrapolated (or interpolated 1) subjective pole of the outward-looking "extroverted" self. The noetic attitude of extroversion is that which manifests (or constitutes as known) the exteriority of the empirical object to the perceiving subject.

Extroversion is the primitive intention or orientation of our everyday selves when we move or act intelligently but in a biological pattern, grasping what Lonergan calls the 'already out there now real. '12 Is this primitive intention we called extroversion no more than the passive reflection of an already spatially ordered totality (spatially ordered, that is, in a sense that is independent of the subject's activity in the World and affirmed precisely in that sense), a glimpse of what is independently of the presence and activity of the subject and insofar as it is independent of the presence and activity of the subject? Or is extroversion the active anticipation, based upon the complex sensory and motor activities of man, of certain kinds of objects to be met, touched, used, consumed, desired or feared in his commerce with the World? In the former case, the subject does not contribute by his own activity to the constitution of the empirical object as suchhe merely recognizes it out-there-now; in the latter case, the subject does. In either case, the subject-object relation is an intended spatial one-one, that is, of spatial separation-though as we have seen there are two views (at least 1) as to how spatial relations are constituted as [383] known by the active "extroverted" anticipation of a subject exploring the World through a complex sensory and motor apparatus. ${ }^{13}$ 
There are various kinds of empirical objects. One can distinguish the following: a pure uninterpreted sense datum (supposing that to isolate such an object of awareness were possible); an intellectually categorized sense experience considered as appearance (we call this a phenomenal object); an intellectually patterned experience asserted as noumenally real, e.g. a desk (we call this a full empirical object). The last-mentioned possesses, in addition to empirical objectivity, a type of objectivity we call strict objectivity, to which reference will be made below. A full empirical object is something directly perceived occupying its own space and possessing a certain (spatial) unity and permanence in time; for such an object, I reserve the name body.

Public objectivity is the property of being an object for the members of a certain community. Public objects are then objects recognized in a certain community and so they possess intersubjective value. About them public communication can take place between the members of the community. The contrary of public objectivity is the privacy (a kind of subjectivity) which pertains to those aspects of an individual subject's activity which cannot be shared with a general public, either because they cannot be linguistically expressed or because they do not constitute public and empirically establishable states of affairs in the community's common World. ${ }^{14}$

There are various kinds of public objects of which we shall mention only the two principal types: (i) intentional (or ideal) objects, as for example, the content of a formal definition, a mathematical object like a point or a line or a conceptual model, (ii) states of affairs (ontic realities) in the community's common World. It is this second sense that Heisenberg intended when he wrote in his early empiricist phase: "We can only communicate the cause and results of a measurement by describing the necessary manual actions and instrumental readings as objective events taking place in the space and time of our [384] Anschauung". ${ }^{15}$ Twenty years later, however, Heisenberg, now in his rationalist phase, could distinguish between what is merely objective and what is real. The wave function, he wrote in 1955 , is "objective but not real," ${ }^{16}$ objective, i.e. in the sense that the derivation of its mathematical form is open to all competent persons, but not real, since it does not represent a unique empirically verifiable state of affairs in the World.

While it is perhaps sufficient for the pursuit of science that the objects of science possess both public and empirical objectivity in some of the senses outlined above, it is clear that scientists in fact are not satisfied with just any kind of empirical objectivity-for both mere appearances and reality share this categorynor with just any kind of public objectivity-for they are accustomed to distinguish between mere mathematical models, like the Lagrangian or the wave function, and real states of affairs as observed in nature or during the course of a laboratory 
experiment. We need a kind of objectivity which is capable of distinguishing mere appearance from reality, and mathematical entities from real entities. Common to all these classes is the fact that they are not merely objects of noetic consideration, supposition, inquiry or other merely preliminary acts of knowing, but they are all terminal objects of some form of inquiry, i.e. they are terms of assertion of different kinds. The property of being the terminal object of an assertion, I call strict objectivity. ${ }^{17}$ It has the following properties.

The sense of strict objectivity is to state simply what is independently of the noetic act which makes the assertion-not necessarily, however, independently of all relation to the subject, for what is may in fact be presented or represented under the aspect of its relativity to the subject, as for example, when the subject experiences a likeness of something which is not really present (a mere appearance), or when the object is the product of purely mental construction (mathematical or intentional entities), or even when a reality is known and recognized through its characteristic appearance in the sensory-kinetic experience of a subject, as, for example, lightning as perceived. 'To be' always has the sense of 'to be for (a community of) subjects.'

Moreover, while strict objectivity confers on empirical and public objects that special quality in virtue of which they become in addition [385] terminal objects of the complete cognitive act (i.e. objects of assertion), strict objectivity is not restricted to what is empirically objectifiable or publicly objectifiable. For example, of an electron it can be said "It is," and thus it possesses strict objectivity even though the electron may not be occupying a definite place in space at that particular moment18 Similarly, if there are private objects like selfawareness of which I can say, for example, "My self-awareness is," then these possess strict objectivity, even though they possess neither empirical nor public objectivity.

Moreover, while the objectivity relations which constitute empirical and public objectivity oppose object to subject as contrary terms (see the definitions given above), strict objectivity does not of itself oppose object to subject, for That is is; common to both. subject and object. When the subject makes assertions about' himself ("I am," "I am a knower at this moment"), he is asserting the strict objectivity of subject-as-object. This would be meaningless were the subjectobject relation always such as to oppose subject to object, as, for example, by spatial exteriority (empirical objectivity) or by intersubjectivity (public objectivity). The acceptance of strict objectivity as a valid mode of objectivity different from both empirical and public objectivity is entailed by and in turn explains and justifies the objective character of statements made by the subject about himself and his own intentional activity; i.e. the objective character of the subject's reflexive self-appropriation of himself as a knower, wilier and doer. ${ }^{19}$ 
Since That is is common to both subject and object (as strict objects), we can draw a consequence in the case where subject and object are entitatively distinguished. In this case, the assertion which the subject makes about the object must be accompanied by an implicit reflection on the entitative distinction between subject and object (on pain of identifying subject and object). This entails the formation of an additional (generally implicit) assertion that the subject is not the object. Thus the most general form of the assertion of strict [386] objectivity, in the case where the subject and object are not identical, is: "The object is, the subject is, but the subject is not the object. ${ }^{20}$ The contrary of strict objectivity is not to be looked for in negative statements ("That is not"), for this too is an assertion, but it is to be sought for in the various preliminary acts of inquiry, consideration and supposition, etc., which precede the act of assertion and are ordered to an assertion as to their term and goal. Thus, an object lacks strict objectivity when it is merely the object of inquiry, consideration, supposition, or other preliminary knowing act, but not yet an object of an assertion.

\section{REALITY AND APPEARANCE}

We have mentioned three classes of strict objects: Appearances, intentional objects and realities. Each class can be defined with respect to the characteristic properties of the noetic intention which seeks them out and recognizes them when found. Appearance and reality are directly contrasted within the same noeticnoematic structure: intentional entities are contrasted with the preceding by being the products of purely noetic acts with no noematic complement.

Intentional entities, like mathematical entities, are investigated by a purely noetic intentionality-structure, by which we mean that the truth or falsehood of assertions about mathematical entities is not determined by an appeal to empirical experience, for the World does not contain mathematical entities, but to the defined properties of the intentional entities under consideration. The truth of assertions about the real order, however, unlike that of mathematical statements, depends on a noematic component-that is, on the sensible outcome of some empirical procedure-since the World is identical with the domain of optic realities.

A sensation is not meaningful or intelligible solely by itself; that is, a meaning or an intelligibility is not given together with a sensation. ${ }^{21}$ [387] The belief that an object is meaningful or intelligible insofar as it can be reduced to the contents of sensations is one aspect of what Sellars has called the "myth of the given." ${ }^{22}$ It follows from the rejection of this belief that no accumulation of protocolsentences will make an intelligible theory or explanation. On the, other hand, the presence or absence of a sensible component of a certain kind does indeed help to 
decide the truth or falsehood of an answer. The sense of the answer, however, is not given by or with the sensory datum; it is borrowed from the intelligible structure of the question which preceded it, which directed the resulting empirical part of the inquiry and which consequently sees the sense contents as an answer to its particular question. In other words, particular sensory data are ambiguous, unintelligible, irrelevant and insignificant apart from the context of empirical inquiry to which they respond. To the extent, then, that a sensation carries a borrowed intelligibility, it performs the function of a signal (sign or observable symbol) relative to the message (borrowed intelligibility) it conveys. The intelligibility belongs to the noetic aspect of a noetic-noematic structure. It is only within a noetic-noematic structure that sensory data make sense.

There are, of course, many kinds of noetic-noematic structures. They are as various as there are different structures of empirical investigation. Consequently, a particular sensory datum can take on as many senses as there are different methods of empirical inquiry (heuristic structures) which can be directed to it and to which it responds. For example, a flash of red light in different contexts of inquiry may indicate such different things as a cigarette in a dark room, a burst of electrons in a tube, or additional confirmation of a new particle theory. Given then a particular sensory datum, one can generally bring to bear on it a variety of questions belonging to different heuristic structures of empirical inquiry, and the sensory datum will acquire as many different meanings as there are different methods of inquiry to which its occurrence is relevant. In the language of information theory, sensory data serve as a communication channel. They are elements of a signal space, and like any signal space, its elements can be utilized to transmit messages belonging to a variety of [388] message spaces. The error of psycho-physical parallelism is that it postulates a unique correspondence or "translation" between physical input and cognitional output. ${ }^{23}$ On the contrary, each distinct noetic-noematic structure constructs a distinct message space (corresponding to the noetic component of the structure) linked to a communication channel in sensation (which gives access to its noematic component).

This dependence of the sensory datum upon a prior context of empirical inquiry for its relevance and intelligibility opens the way to the possibility of the spurious intelligibility of a mere appearance. A judgment about a mere appearance denies neither the reality of the sensory data themselves nor of their real causes but is concerned to deny reality only to that of which, within a certain context of empirical inquiry, the sensory data would be a typical manifestation (or appearance).

The distinction between reality and appearance is then relative to the heuristic structure of empirical inquiry envisaged. A method of empirical inquiry results in 
a noetic-noematic structure, one belonging, for example, to a common sense mode or to a scientific mode. This noetic-noematic structure outlines a horizon of reality within which some real objects at least are capable of being attained. Let us suppose that a particular subject in a concrete situation is led, rightly or wrongly, to anticipate that a certain structure of empirical inquiry is the correct one for the situation. He sees, for example, a darting glowing ball of light in the sky and being accustomed within the common sense mode of inquiry to associate stable spatially unified appearances with the existence of a physical body, he concludes uncritically that he has seen a flying saucer. Another subject, experienced in the observation of electrical atmospheric discharges, withholds his judgment within the common sense frame, admitting nevertheless that the phenomenon has a flying-saucer-like appearance within that frame, and asks himself instead whether a scientific investigation would not reveal that the phenomenon is really due to electrical [389] atmospheric discharges and not to a physical body in the everyday sense. Neither of the two observers disputes the sensory appearances, but the second observer for whom alone the distinction between reality and appearance is an actual issue, disputes that their correct interpretation is to be sought within the noetic-noematic framework of common sense with respect to which in the instance cited the distinction between appearance and reality is made.

We can return now to the question from which we departed to make this lengthy detour on the notion of objectivity, that is, to the question of specifying with greater precision the meaning of the term 'real.' The definition we proposed above was that whatever makes its appearance or could make its appearance directly or indirectly as one of the objects in the World is real, and vice versa. It is now clear that we must restrict the meaning of the term 'object' to strict object of the class of those attainable within a poetic-noematic intentionality structure (i.e. by a valid method of empirical inquiry). These objects will be public objects. They will not necessarily be empirical objects, however, for only those which make their appearance directly in perception are empirical objects. These objects will manifest themselves through empirical signs (observable symbols) and Hence they will make their appearance at least indirectly in perception; but definite location in the space of perception, a characteristic of an empirical object, might conceivably be lacking to the strict object. The most immediate instance that comes to mind of the latter category is an electron of definite momentum. However, as we shall try to prove, no physical variable insofar as it is part of a scientific explanation is directly perceptible. A physical variable is essentially unrelated to human perception or to the goals of human activity and makes itself known in human awareness only' through the interpretation of the sensible symbols of its presence. Physical variables insofar as they are observable are, then, always and necessarily never more than indirectly observable. 


\section{SCIENTIFIC HORIZON AND COMMON-SENSE HORIZON}

A horizon is the set of optic realities manifested or capable of being manifested to a human subject within a given noetic-noematic structure. To each distinct noetic-noematic structure there corresponds a distinct horizon and vice versa. The totality of all horizons is called the World. ${ }^{24}$ [390] Every ontic reality makes its appearance within a particular horizon; that is to say, it is or it could be a strict object of the noetic-noematic structure to which the particular horizon corresponds. Consequently, every ontic reality manifests itself to a human subject within a prior context involving the subject, a certain empirical method of inquiry (which specifies the horizon) and the other objects occupying the horizon in question. These relationships are a priori to this or that empirical experience (though not to all empirical experience) in the sense that they are precontained in the kind of question one chooses to ask of experience. The mere asking of a question however does not guarantee that this question is the relevant one to ask in the circumstances (apt, that is, to render the sensory data intelligible), nor does it determine a priori the quality of the response which experience will give--whether affirmative or negative. The relationships are a posteriori to empirical experience in the sense that new empirical data, which cannot be rendered intelligible by the light of any of the noetic intentions of which the subject is already master, provokes the desire for a new insight which, when obtained, leads to the construction of a new noetic intention, and which in turn leads to the constitution of a new horizon.

Accordingly, when one recognizes a particular ontic reality, e.g. a desk, or an electron impact, one recognizes it as the term of a complex set of ordered relations which converge on the subject through the fact that it is related to the subject as a term reached by the subject using a certain method of empirical inquiry. Since, as 1 have already said, sensory data serve within a noetic-noematic structure merely the function of a communication channel relative to the strict objects which constitute the message (or meaning) space, it is clear that the [391] meaning of terms like 'desk' or 'electron impact,' etc., is to be sought in the message space rather than in the signal space. This entails that the meaning of these terms is not reducible to mere combinations of symbols (that is, of sensory data) in the signal space. The message space, however, is no more than a list of propositions about certain kinds of things, properties and relations insofar as these are or could be related to the inquiring subject by the method of empirical inquiry which constitutes the noetic intention in question. For this reason, every ontic reality (thing) insofar as it is known is a thing-for-subject, where the hyphens indicate that a horizon and a corresponding noetic-noematic intentionalitystructure are implied-a horizon within which the thing reveals itself to a subject as 
real and a noetic-noematic intentionality-structure within which the thing in question is or could be a strict object for the inquiring subject.

Several consequences follow from this. In the first place; the nature (or essence) of a thing (what we understand when we ask the question: what is this thing?) is not given to us in any absolute fashion, independently, that is, of its relationships to other things or to the inquiring subject. The essence of a physical thing is, as far as we are concerned, to be a term within a complex relational structure constituted by a certain method of empirical inquiry. This, then, is what every concept expresses-not the content of an intuitive "look." into a closed essence as if an essence were a private thing like the inside of a black. box but a complex relational structure involving relations to other things or to human subjects. ${ }^{26}$ Such a relational structure within which something gets its definition I call an ideal relational norm $2^{7}$ A particular kind of thing may of course enter as a related term into a variety of different relational structures. If this is so, then it would appear to have more than one definition and more than one essence (depending on the number of ideal relational norms in terms of which alternative definitions could be formulated). It is sufficient for us to distinguish here just two general kinds of ideal relational norms: one relates a thing to the perceptual and purposive life of a human subject and is characteristic [392] of common-sense horizons of reality-this I call a thing-to-subject-for-subject; the other relates a thing to the dynamic patterns of interrelated activity between things (omitting the human subject from the circle of defining relations) and is. characteristic of the horizons of reality reached by the physical sciences-this I call a thing-to-thingforsubject (or a thing-to-instrument-for-subject) ${ }^{28}$

In the second place, insofar as every method of empirical inquiry involves types of behavior (excluding for the moment linguistic behavior) through which the subject explores a horizon of reality, the meaning of any term involves reference to the types of behavior through which the reality is attained and to which it is understood to respond. For example, a familiar form of common sense heuristic behavior is the attentive use of one's sensory-kinetic powers (to see, touch, move around things, etc.); another form of common sense behavior is the search for something to fulfil a need or desire (for food, for bodily comfort, for, convenience say in writing, etc.); scientific heuristic behavior often involves putting things together so that they interact in a controlled way and give information about the underlying physical processes and parameters. In all the examples given, the behavior aspect characteristic of a particular noetic-noematic structure is combined with an intentional aspect; that is, not merely does the behavior pattern guarantee that a certain inquiry has an empirical content by establishing a physical communication channel between subject and object, but in so doing it also sets up or completes the complex pattern of physical relationships 
between subject, object and horizon which is essential to what is meant or indicated by the inquiry (i.e., to its message or meaning-space). The structure of these relationships also determines the kind of definitions which the inquiry will produce, i.e. what form the ideal relational norm will have.

Finally, the flexibility and utility of a particular noetic intention will depend upon the subject's ability to recognize the types of behavior which could incorporate the noetic intention in question. For example, a thirsty man accustomed to drinking liquids from a tap or a bottle may fail to recognize coconuts as a source of thirst quenching fluid. Or again, a physics student who has been taught only one way of measuring mass may fail to realize that the physical theory he. knows, if applied imaginatively, could yield an indefinite number of mass-measuring apparatuses. Behavior, then, is relevant to meaning only [393] insofar as the structure of behavior is correctly understood to incorporate a definite noetic intention, and is used with this intent. Common sense realities and the scientific realities of physics belong evidently to different horizons of reality. We have already mentioned the most general feature which distinguishes common sense horizons, on the one hand, from scientific horizons, on the other. The importance of the distinction we have made between thing-to-subject-for-subject and thing-to-instrument-for-subject arises from the prevalence of two widespread beliefs. One, entertained, for example, by Bohr and Heisenberg, is that only common sense concepts are capable of expressing real states of affairs, and consequently that physical theories like quantum mechanics or the theory of relativity, which depart from the norm of common sense or from the allegedly more refined versions of common sense concepts used in classical physics, are incapable of expressing real states of affairs. ${ }^{29}$ A related belief also very widespread is that the horizon of scientific reality is no more than an extension of the horizon of common sense objects. Both views attach the character of reality exclusively to objects recognizable by common sense structures of knowing. It was the purpose of the preceding analysis to explain how and why the author thinks this viewpoint is mistaken.

The difference between common sense concepts and scientific concepts is summarized in the following propositions:

1. Common sense concepts have a logical structure of their own different from those of physics, whether classical or quantum. This logical structure is summarized in the formula which describes common sense horizons as horizonsof-things-to-subject-for-subject. ${ }^{30}$

2. Physical concepts, whether classical or quantum, have the logical structure of thing-to-instrument-for-subject concepts and are consequently by definition unrelated, except indirectly through the interpretation of observable symbols, to 
perception or to human. purposive activity. Scientific physical concepts, then, possess a different logical structure from that of common sense-concepts. ${ }^{31}$

3. physical concepts, no less than common sense concepts, can be used to express real states of affairs. These real states of affairs define a scientific realityhorizon which we called a [394] horizon-of-thing-to-instrument-for-subject)? ${ }^{32}$ The full World of reality is made up of the totality of common sense horizons and scientific horizons.

Let us pursue this comparison between the scientist and the man in the street. The man in the street knows things by the way they appear in perception. He recognizes the things that satisfy his needs; he knows how things can be manipulated to produce desired ends. The World of reality of the man in the street is a world saturated and tense with desire and with seductive calls to movement and activity. It is a World manifested to man mainly through a pattern of teleological drives. Aristotle and all the ancient philosophers saw this clearly. Phenomenology has re-discovered this fact. The man in the street looks out on reality as the ordered totality of actual and possible objects related to him as a center of activity, as Dasein. The man in the street is there, $D a$, in the midst of things and persons, not in the merely passive spectator sense of being situated at the center of perspective of a picture, but he is a presence among things and persons in active rapport with his environment. He lives, as it were, in a dynamic intentional field constituted by the presence of other people and things. He influences this field and it in return influences him through the resonances it arouses in the dynamic patterns of his life. The concepts and language of the common sense World are those appropriate to the horizon of reality I have just described. I have called it a horizon-of-things-to-subject-for-subject.

The scientist, too, is concerned with reality but in a different way. He uses instruments where the man in the street uses his eyes, ears, hands and feet. The scientist by his actions may seem to cast doubt on the accuracy, precision and trustworthiness of the naked senses, for he is disciple of Democritus, Pythagoras and Galileo in his distrust of secondary qualities. His search for "objective" science unaffected by private and personal influences leads him to use instruments. In order to understand What instruments do, he is obliged to formulate physical theories and to use sets of theoretical constructs which refer to no immediately sensed objects but help him to understand measurement processes. It is the measurement process and the use of instruments in science which are the key to the logic of science and which explains the peculiar nonintuitive properties which some scientific realities have, like the Indeterminacy Relations for position and momentum, the apparent emptiness of the atom and the paradoxes of relativity. 
The instrument is a kind of vicarious observer, replacing the subject and the rich variety of his perceptive and emotive relations to reality [395] with a robotthing capable of contacting objects only in a limited and predictable number of ways and these strictly physical ways. What the physical scientist is trying to do is to understand how the robot-instrument "experiences" the things around it and "organizes" them from its own vantage-point into a dynamic pattern centered on itself. The robot-instrument, however, is neither conscious nor does it act purposively: it has no true experience in the sense that a living body experiences. It interacts with other things because the scientist has so arranged it. The structure of its "experience" is really the pattern of its interactions with reality. It is this pattern of interrelated activities which it is the goal of physics to express. This is what the theoretical language of physics intends to express. ${ }^{33}$

In order to study the pattern of interactions, the scientist has to put things together, observe dials and perform experiments. He must exert himself physically. This part of the scientist's activity belongs to the common sense world, and to describe what -he does within it one uses an extension of common sense language generally called observational language. A physicist then uses two languages: a theoretical (explanatory) language, which expresses the horizon-ofthing-to-instrument-for-subject, and an observational language, which describes his commerce with the common sense horizon-of-things-to-subject-for-subject.

Since all physical variables and entities, like electrons or electric field intensity, are defined in relation to definite kinds of instrumental contexts, they never enter directly into the common sense horizon-of-things-to-subject-forsubject. They are not directly observable. This worried many philosophers of science. Rankine and Mach, for example argued that theoretical entities were divided into hypothetical entities like atoms, which were imperceptible, and abstractive entities, like distance, which were perceptible. Only to the abstractive entities would they attribute a genuine reality-status. However, consider one such variable, say distance. Can it be said truly that distance as it enters physics possesses the same formal essence as distance-as-perceived? Does it share the same definition? Distance enters physics as distance-as-measured and both quantum mechanics and the theory of relativity have shown that distance as a physical quantity can have properties quite at variance with the properties of distance as abstracted from the intuitive perception which characterizes the common sense world of everyday experience. 'Distance' connoting the physical variable pertains to the theoretical language of science [396] 'distance' connoting perceived distance pertains to the observational language of common sense. The fact that the same word is used within two such different epistemological contexts as the horizon-of-things-to-subject-for-subject and the scientific horizon-ofthings-to-instrument-for-subject, with consequently different meaning-structures 
for the same term, illustrates the point that has already been made, that the same object language term might be used in different relational contexts as referring to different ideal relational norms. Such a term would no longer be univocal. Nevertheless there would generally . exist sufficient kinship between the various meanings of the term to warrant calling the term 'analogous' in its usages rather than 'equivocal.' This leaves as an open question the kind of similarity (material identity of referent, similarity of function within the different relational contexts, etc.) on which the analogy in any particular case ultimately rests. This ambiguity about the meaning of apparently ordinary common sense words is a rich source of paradoxes often exploited by popular scientific writers like Gamow, Jeans and Eddington. A good example is that of the two tables-the "substantial" commonplace table and the "insubstantial" scientific table-expounded by Eddington in the preface to The Nature of the Physical World.

\section{CORRESPONDENCE RULES}

Objects in the observational framework are real, and so too, according to the analysis of objectivity given in the earlier part of this paper, are the objects of the theoretical framework. Reality is not a characteristic only of a set of observational horizons but it also characterizes the set of scientific horizons. The question arises: how are these two kinds of realities related to one another.

According to the explanation given, a horizon is manifested through a set of signs. Sense experience and the experience of purposive bodily activity are the signs which manifest the horizons of observational events and things. Observational events and things in their turn are the signs which manifest the horizon of scientific entities. In both cases, the appropriate reality-horizon is manifested through the interpretation of a corresponding signal space. In the case of the observational framework, the signal space is the set of sensible and bodily impressions resulting from our common-sense commerce with nature; in the theoretical framework, the signal space is a subset of common-sense events or things, namely, those affected by our scientific commerce with nature. [397]

From this account, it would seem to follow that the picture of scientific theory as composed of a set of theoretical terms linked to observational terms by correspondence rules is defective, in all those forms at least where an attempt is made to reduce the sense of the theoretical terms to the sense of the observational terms; that is, to equate the sense of 'a theoretical term with a special complex combination of senses belonging exclusively to observational terms. ${ }^{34}$ Correspondence rules do not "translate" theoretical terms into observational terms, for translation presupposes two sets of symbols defined over a common field of meaning, while here we have two fields of meaning as well as two sets of symbols. 
Certain sets of observational statements belonging to the description of measurement processes constitute as we have said a signal space. The message space associated with this signal space is the set of theoretical statements. Correspondence rules then set up the one-to-one or many-to-one correspondence between these two spaces. Such a correspondence involves a "levels picture" of scientific theory, but one in which the higher level of meaning is not reducible to the lower. Objects of the lower level of meaning are needed by us because they constitute the only available communication channel through which we can discover the character and existence of objects of the higher level, but they are not parts out of which the higher level objects are composed ${ }^{35}$

It has been proposed by some authors that the correspondence rules mean to affirm identity of denotation between an object (or object-complex) of the observational framework and an object (or object-complex) of the theoretical framework. This recognizes that the difference in meaning between observational and theoretical, terms arises out of the different contextual situations to which they refer, and asserts merely the material identity of the subject matter considered in the different contexts. Consider, for example, the following sentence which one might suppose on the basis. of this theory had the form of a correspondence rule: ' A table is such and such an array of vibrating atoms in bound states.' The grammatical subject ('table') uses observational language and stands for the observational table; [398] the predicate uses theoretical language and stands for what we might call the scientific table. Does the term 'table' refer to one and the same optic reality or to two different optic realities (ignoring for this purpose the question as to whether the observational table is one optic reality or an aggregate of them, and likewise the scientific table)?

The verb 'is' is used in the above sentence in a special way that merits attention. It binds an observational language subject to a theoretical language predicate. To what language does 'is' itself belong? Evidently to the metalanguage. But it does not denote complete or even partial identity of sense between subject and predicate, for the sentence is neither a redefinition nor a translation nor does it express a property or quality of the observational table (for the predicate does not refer to the same horizon as the subject). It has been suggested that perhaps its correct formal transcription is the following:

(x) ( $\mathrm{x}$ is table <-> $\mathrm{x}$ is an array of vibrating atoms, etc.) $\quad$... (I)

where the predicate uses theoretical language and stands for what we might cal the scientific table. Does the term 'table' refer to one and the same optic reality or to two different optic realities (ignoring for this purpose the question as to whether the observational table is one optic reality or an aggregate of them, and likewise the scientific table) $\mathrm{T}$ 
The verb 'is' is used in the above sentence in a special way that merits attention. It binds an observational language subject to a theoretical language predicate. To what language does 'is' itself belong? Evidently to the metalanguage. But it does not denote complete or even partial identity of sense between subject and predicate, for the sentence is neither a redefinition nor a translation nor does it express a property or quality of the observational table (for the predicate does not refer to the same horizon as the subject). It has been suggested that perhaps its correct formal transcription is the following: the expression on the left is entirely in the observational language, the expression on the right is entirely in the theoretical language, and $\mathrm{x}$ denotes the common subject matter. Superficially (I) seems to have the logical form of a definition. But it must be remembered that the expression on the left and the expression on the right belong to different languages. They are not interchangeable, and, consequently, (I) is not a definition. ${ }^{36}$ The subject matter is that about which a statement is made and which the statement describes or explains. In the case of the sentence form 'x is a table,' the appropriate subject matter referred to by $x$-is something already judged to belong to the horizon of common sense; that is, the sense impressions which signalize to me the existence of a table are already taken as signs to be interpreted according to a certain noetic-noematic structure, that, namely, of common sense. In the case of the sentence form ' $x$ is an array of vibrating atoms, etc,' the subject matter is something already.judged to belong to the horizon of physical science, for which the appropriate observable signs will be events or objects in the common sense horizon. [399]

The form of (I) requires that the same identical reality is both an object in the common sense horizon and an object in the horizon. of physical science. It is entirely possible even in our account that some common sense object, like the moon, be both a thing-to-subject-for subject through being perceived and a thingto-instrument-for-subject through its relation to the earth's tides, but it is not necessary that this be so for every scientific object. It is clear that many theoretical entities cannot be directly related to sensibility as, for example, a single electron or a single atom. In fact, our epistemic analysis of the typical measuring process makes it clear that direct sensible contact is presupposed only between the subject and the instrument. From the perception of the instrumental response considered as an observable symbol the subject concludes to the existence and state of the scientific object which as such does not enter the perceptual field. From the response of an ionizing counter, for example, one concludes to the existence and energy of the election that triggered it ${ }^{37}$ The scientific table exists but its existence is not existence in perceptual space and time; it is not an already-out-there-now-real in Lonergan's terminology, that is, an object of biological extroversion. The scientific object is a strict object where strict 
objectivity implies a meaning for reality (or physical existence) which goes beyond that of empirical objectivity. .

To return, then, to the sentence (I), it is clear that although in some cases correspondence rules might have this form, it is not the most general form which correspondence rules take. Correspondence rules would seem to work in the following way. The observational language describes the instruments, events and the environment significant to a measuring process as these are present in the common sense horizon. The correspondence rules then state that events in the observational framework are observable symbols justifying certain assertions in the theoretical language. The formal transcription is like a reduction sentence,

$$
\mathrm{P}_{\mathrm{O}--}>\left(\mathrm{Q}_{\mathrm{O}}(\mathrm{x})<-->\mathrm{R}_{\mathrm{T}}(\mathrm{y})\right)
$$

where $\mathrm{P}_{\mathrm{O}}$ and $\mathrm{Q}_{\mathrm{o}}(\mathrm{x})$ are in the observational language and $\mathrm{RT}(\mathrm{y})$ is in the theoretical language, $\mathrm{P}_{\mathrm{O}}$ describes the significant environment or construction of the measuring process, and $\mathrm{Q}_{\mathrm{o}}(\mathrm{x})$ describes a particular instrumental response. In (II), $P_{O}$ affirms a real context within the horizon of common sense. $Q_{0}(x)$ affirms a real event of a certain [400] type (e.g. the movement of a pointer; while the set of possible movements would be denoted $\left.\left\{\mathrm{Q}_{\mathrm{o}}(\mathrm{x})\right\}\right)$ and $\mathrm{R}_{\mathrm{T}}(\mathrm{y})$ affirms a real event of a certain kind within the scientific horizon (the set of possible events of this kind would be denoted by $\left.\left\{\mathrm{R}_{\mathrm{T}}(\mathrm{Y})\right\}\right) .38$ It should be noted that the ordinary logical signs of implication, biconditionality, etc., do not adequately translate the nuances of the epistemic analysis, for they give no clue to the relation of signal to message that exists between the objects designated by the set $\{$ Qo $(\mathrm{x})\}$ and the object designated by the set $\left\{\mathrm{R}_{\mathrm{T}}(\mathrm{y})\right\}$, or to the fact that the two antecedents belong to one language, an observational language, and that the final consequent belongs to another language, a theoretical language. This brings us to the next point which is relation between language and intentionality. A particular language is the product and expression of a particular noetic intention. Observational and theoretical languages are then diversified by the variety of noetic intentions which they express.

\section{LANGUAGE AND INTENTIONALITY}

A language can be defined as a formal calculus endowed with a semantical or pragmatic interpretation. We are actually concerned in. what follows only with the semantical aspect of language, that is, with its use to "speak out" or indicate objects other than the attitudes and dispositions of the subject. Logicians concern themselves with the completeness and consistency of the language as a formal calculus. A well constructed calculus will then possess a formal unity, the outcome of its syntactical structure. Does the formal unity of a language correspond to some real unity among the field of objects intended when the language is used? There are three possibilities. The unity of the language's use could be due to the 
subject's unique functioning intention imposing such a unity where no such natural unity existed; or it could be a characteristic of the field of objects to which, it refers independently of the subject's intention; or it could express two different but mutually complementary aspects, namely. both the unity of a subject's functioning intention and the unity of a horizon of objects towards which the intention is turned. [401]

The solution to this problem has already been given in an earlier part of this article. An object is known only to the extent that an affirmative noematic response is obtained to a (at least implicit) question the formulation of which supposes a prior noetic intention embodied in certain procedures of inquiry. The subject explores reality by reaching out towards it with the aid of tentative heuristic intentions guiding systematic methods of inquiry. Some of these turn out in practice to be fruitless, others prove to be of more or less utility in man's commerce with reality. It seems then that to each distinct functioning noetic intention on the side of the subject and consequently to each distinct horizon on the side of reality, there corresponds a language which "speaks out" in public symbolic form both the heuristic structure of the subjective intention and the anticipated objective structure or pattern among the objects which constitute the horizon. A horizon is defined as the totality of actual and possible (strict) objects attainable by a single empirical method of inquiry. It seems then that a language--as opposed to a system of languages such as a natural language like English (French, German etc.) is--could be defined as that part o€ a natural language which expresses a unique functioning noetic intention and (consequently) a unique horizon. As there are many different functioning noetic intentions, so there are many different horizons of reality and consequently many different languages, one corresponding to each horizon. It is then of some interest and importance to determine what these intentions are that man uses to explore reality, to discern whether man is capable of inventing radically new intentions, whether old intentions have been abandoned in favor of new ones and to discover whether particular communities possess more or less private though nonetheless valid intentions which give them as it were a special privileged window on reality which other communities do not share. What has been said about noetic intentions is also true of the different languages a person uses, for a natural language, like English, being itself a conglomerate of many languages, each expressing a particular horizon of reality accessible to speakers of English.

How can a person know that another person is speaking the same language as he is? Let us suppose that two people are using the same vocabulary and the same syntax. One could verify the identity of the functioning intention to which the language gives expression by interrogating a person about the empirical procedures he would use to verify or falsify particular statements expressed in the 
language he is using. Now an empirical intention is always incarnated in certain characteristic empirical procedures of inquiry. These constitute [402] a form of behavior which can be publicly examined. He who would always do the same things to verify or falsify a statement of a language as I should, must mean the same horizon of objects as I mean when I use the language. That is, if in pursuit of a noematic response, we always engage in the same heuristic behavior, then we share the same intention and have a window on the same horizon of reality ${ }^{39}$

The discernment of the number and variety of separate languages which go to make up a natural language (say, English) would seem to be a very complex and difficult problem. One would surmise that a word or a sentence may well occur in a variety of languages and that its use may be such as to express events or things belonging to a variety of different horizons. The actual semantical meaning of a term or a sentence, then, cannot in general be determined from the words alone, but recourse must be had to the way it is used by a speaker in a particular case. This will involve discovering the particular intention used by the speaker and, if it is an unfamiliar one, analyzing its structure. Only when the nature of the noetic intention has been clarified is one in a position to construct the language associated with it and to express the horizon of reality modeled linguistically by this language.

How would one determine in practice the vocabulary, syntax and semantic rules which constitute a single language? One method that might be suggested is the use of a dictionary. Starting with some non-logical word, like horse, one goes to the dictionary and looks up its dictionary definition. All the non-logical terms contained in this dictionary definition are then listed. Then one looks up in turn all these terms and one adds to the list the non-logical terms that appear in the dictionary definitions of each. One continues this process until no new terms are added to the list. The set of terms so collected is closed-relative, of course, to this dictionary. A plausible suggestion might be made that this set of words together with the logical vocabulary comprise a single language. This hypothesis, however, might be false for a variety of reasons, quite apart from the relativity to the dictionary employed. In the first place, a good dictionary lists a variety of meanings far a particular word and it would soon become clear that not all the definitions proposed by the dictionary are equally [403] relevant to the task we have set ourselves of mapping the linguistic structure of a single functioning intention. The same word or sentence may well be part of several different languages. In the second place, it might be objected that the procedure outlined would ultimately lead one to include every term in the dictionary. That, I think, is unlikely. Though if it did happen, it would certainly invalidate the suggested procedure. 
Another method that might be suggested is that of intentional analysis. This would involve research into the basic. noetic intentionality structures which a person uses to explain or describe his environment. The uniqueness of a language is determined by the uniqueness of a functioning intention. To each analysable noetic intention, there will correspond a language with a usage prescribed by this intention. For example, by looking, touching and moving around, we build around us an awareness of objects in perceptual space and time. Perceptual language used to model the perceptual horizons of reality gets its meaning then from the empirical procedures involved in looking, touching and moving around objects. Through purposive activity, for example, in the search for food and for the satisfaction of one's needs and desires, one orients oneself towards a horizon of objects recognized by their relation to one's purposive activity. The language appropriate to this kind of cognitive activity (let us call it operational language) may contain besides the terms proper to itself other terms belonging also to the perceptual language. This points up the important conclusion that no word or sentence is endowed with a unique meaning, but that its actual meaning in use depends on the noetic intention employed by the speaker, that is, on the language the speaker is actually using. The meanings of words and sentences, then, are not divinely pre-established, but are relative to human modes of heuristic activity. These heuristic modes change with the bodily constitution of men, with their culture, needs, environment, the nature of their commerce with their environment and their insight into this. ${ }^{40}$

In the early part of this article, I distinguished two general classes of noeticnoematic intentionality-structures: those characteristic of common sense and those characteristic of science. To 'each accordingly, there belongs a language-typecommon sense languages to common sense horizons and scientific languages to scientific horizons. A common sense language then is one which expresses a horizon of [404] relevant to the task we have set ourselves of mapping the linguistic structure of a single functioning intention. The same word or sentence may well be part of several different languages. In the second place, it might be objected that the procedure outlined would ultimately lead one to include every term in the dictionary. That, I think, is unlikely. Though if it did happen, it would certainly invalidate the suggested procedure.

Another method that might be suggested is that of intentional analysis. This would involve research into the basic. noetic intentionality structures which a person uses to explain or describe his environment. The uniqueness of a language is determined by the uniqueness of a functioning intention. To each analysable noetic intention, there will correspond a language with a usage prescribed by this intention. For example, by looking, touching and moving around, we build around us an awareness of objects in perceptual space and time. Perceptual language used 
to model the perceptual horizons of reality gets its meaning then from the empirical procedures involved in looking, touching and moving around objects. Through purposive activity, for example, in the search for food and for the satisfaction of one's needs and desires, one orients oneself towards a horizon of objects recognized by their relation to one's purposive activity. The language appropriate to this kind of cognitive activity (let us call it operational language) may contain besides the terms proper to itself other terms belonging also to the perceptual language. This points up the important conclusion that no word or sentence is endowed with a unique meaning, but that its actual meaning in use depends on the noetic intention employed by the speaker, that is, on the language the speaker is actually using. The meanings of words and sentences, then, are not divinely pre-established, but are relative to human modes of heuristic activity. These heuristic modes change with the bodily constitution of men, with their culture, needs, environment, the nature of their commerce with their environment and their insight into this. ${ }^{40}$

In the early part of this article, I distinguished two general classes of noeticnoernatic intentionality-structures: those characteristic of common sense and those characteristic of science. To 'each accordingly, there belongs a languagetype-common sense languages to common sense horizons and scientific languages to scientific horizons. A common sense language then is one which expresses a horizon of thing-to-subject-for-(-a-community-of-)-subjects. A scientific language is one which expresses a horizon of thing-to-instrument-for-(-a-community-ofscientific-)-subjects. Scientists, however, are obliged to use two languages: the observational language of common sense to describe the sensible characteristics and construction of instruments and a theoretical language to express the objects attained instrumentally, that is, through the mediation of a measuring process. These objects constitute the true scientific horizon.

\section{FUNCTION OF THE INSTRUMENT IN PHYSICS}

The horizon of reality to be attained by scientific physical inquiry is the horizon of instrument related strict objects. It now becomes necessary to specify more exactly the function which the instrument and the measuring-process play in physics.

There are a variety of views on this point. I list some of them for the contrasts they offer to the one about to be presented. In the first place, there is Bridgman's operationalism which states that the particular measuring instrument defines the physical property. P. W. Bridgman wrote: ". . . the concept is synonymous with the corresponding set of operations.... We must demand that the set of operations equivalent to any concept be a unique set, for otherwise there are possibilities of ambiguity in practical applications which we cannot admit." ${ }^{41}$ It would then 
follow that as many different definitions of a particular physical property can be given as there are different measuring instruments for it. But as the set of possible measuring instruments for any physical property is indefinitely great, one is left with the problem of explaining what is common to this infinite multiplicity that makes it a class of measuring instruments of a unique physical property. Evidently it is some form of invariance which is prior to any particular measuring process and which makes possible the variety of measuring instruments. The physical property would be identified with this invariance. In fact, reflection shows that any analysable physical process involving a parameter car, be used as a measuring process for this parameter. A measuring process, then is not a special kind of process - with due respect to Margenau - but [405] a special kind of use to which any analysable physical process can be put. $^{42}$

In the second place, there is the view based upon an assumed identification of the horizon of physics with an extension of the horizon of common sense objects. The function of the measuring process then would be twofold: to add intersubjective verifiability ("objectivity") to observed data, and to reveal what is under ordinary circumstances either hidden from the gaze of individual subjects (because for example it is too small) or only vaguely and indeterminately distinguishable by the unaided senses (as, for example, precise degrees of heat). Now common sense objects are reached through their direct relation to the subject's senses and purposive activity in the World, but scientific objects are revealed through their interaction with instruments. Scientific properties are then essentially by reason of their definition not directly perceptible to naked human senses-not because they are below or beyond the threshold of sensibility but because as physical variables they are simply not directly related to human senses or purposive activity.

In the third place, there is the view that the function of the measuring instrument is to manifest what is there before (Margenau) or after (von Neumann) the measuring process takes place 43 Both of these positions are open to serious objections, implying as they do that the goal of physical science is to describe what nature is like independently of any relationship it might acquire to the subject directly or to the instrumental arrangements which function as part of the measuring process. It seems to the author that the measuring not it is possible in particular cases to extrapolate to earlier or later periods of time. This is the partial truth contained in Heisenberg's insight that physics ought to concern itself solely with observation-events and not with hypothetical unobservable structures.44 This [406] is the same partial truth contained in Bohr's insight that the very act of measurement in some way makes real what was only virtual before the measurement.45 In other words, physical variables whether of classical or quantum physics refer to the possibilities of interactions between things. They 
indicate the structure of the dynamic interrelationship of things among themselves-the horizon of thing-to-instrument-for-subject. The formal mathematical aspect of the physical theory expresses the interrelatedness of the variables among themselves through the procedure of implicit (intrinsic or syntactical) definition. To this formal aspect corresponds in the 'horizon of reality to which it refers the set of elementary physical activities which are mutually interrelated into one dynamic pattern. It would. then follow that if all the elementary activities of the interrelated dynamic pattern were to be controlled except, say, two, then these two would consequently be correlated and either one could be used for the measurement of the other. In this way, provided one has sufficient control over the elementary processes involved, any analysable physical process could be used as a measuring process. ${ }^{46}$

Finally there is the view mentioned above that the goal of physics -if it is to deserve the name knowledge is to discover what reality is like independently of any relationship it might have to subjects or to instruments or to other things. This view supposes that what the measuring process tries-possibly ineffectually-to investigate is not the structure of the physical interactions which occur during the measuring process itself, but the objective state of nature where 'objective' is used in a more extreme sense than any that has yet been described. Nature is considered as a "black box" and the scientist tries-successfully or unsuccessfullyto "look" into the "black box" or to make it "translucent" to our "gaze." The content of such a scientific "look" or "gazing" is said to be objective in this special sense. Put in characteristically Newtonian terms, the scientist ambitions to "see" nature as God's eye might be thought to "see" it "objectively," [407] that is, 'with no reference to merely human instruments of research ${ }^{47}$ Such a view of knowledge, (ideal) science and objectivity characterizes Cartesian rationalism, what is also called objectivism ${ }^{48}$ Bohr and Einstein both apparently subscribed to this meaning, at least where macrophysics is concerned, and it is latent in much of the current discussion about the objectivity, or rather the lack of it, in quantum mechanics.

The reasons for rejecting objectivism are the following: ${ }^{49}$

1. Every object is an object for-a-subject; that is, it is revealed by and proportioned to a certain method of inquiry which connotes a subject who inquires. Objective human knowledge is the outcome of valid human methods of inquiry. What it means to be an object of divine knowledge or an object for the Absolute Spirit is very much a mystery to us.

2. The obscure is not to be explained by the more obscure--in this case, scientific objectivity, which is a form of human objectivity is not elucidated by bringing in the mystery of God's objective knowledge of the earth. 
An "objective" account in the sense just mentioned was indeed the implied goal of. many classical physicists; it was the Newtonian ideal. ${ }^{50}$ No problem arose as long as the means used to observe nature did [408] not interfere with the antecedent state of nature; i.e. in the domain of macroscopic physics. In the domain of microscopic physics, however, where the only means capable of channelling information to the human observer about the invisible realities of the microscopic world (e.g. scattered photons, etc.) interact with nature generally to alter its antecedent state, a problem arose. Did such an interaction render impossible an "objective" account of microphysical reality? Many physicists, like the early Bohr and Heisenberg, subscribed to a theory of the measuring process which has been aptly called the perturbation theory of measurement. ${ }^{51}$ As result of Bohr's famous controversy with Einstein, this account of the measurement process was generally abandoned in favor of a relational theory of measurement like the later Bohr's or von Neumann's. ${ }^{52}$ But as far as I can recall, among the criticisms made of it none was directed against the notion of objectivity which it presupposed. What can be said positively about the measuring process?

Operative in the measuring process are two factors, (i) the set of analysable elementary physical processes, and (ii) the use of certain aspects of these processes to obtain information about one of the physical variables taking part in the process. The first of these factors is not sufficient to characterize a measuring process as such; it is a necessary but not a sufficient condition for a measuring process. The characteristic of a measuring process is the use of certain aspects of a physical process to obtain information. A measuring instrument qua physical reality is then no different from any other physical reality. It possesses, however, a certain simplicity of design. That is to say its physical behavior when in the presence of the kind of object which it is designed to measure is sufficiently well understood that correlations can be established on the basis of a physical theory between the property to be measured and some publicly observable effects of the [409] interactions, for instance the positions of a pointer on a dial. A standard measuring instrument is then no more than a convenient calibrated help towards performing a measuring process. The design and construction of measuring instruments is a matter of ordinary physics, in particular of the relation between macrophysics and microphysics and between classical physics and quantum physics. ${ }^{53}$ There is no new, esoteric theory of measurement apart from ordinary physics; unless it lies perhaps in the development of the points that follow.

A physical process is a measurement however only when it is used to 'obtain information abut one of the physical variables involved in the measuring process. The use in question is not a physical use but an informational use, the use of a thing or event as a sign to be interpreted in the light of an accepted code. The sign in question is the observable result of the measuring process and this constitutes a 
channel of communication conveying information about the not-directly observable aspects of the underlying process--namely the thing-to-thing relations characteristic of the dynamic pattern of interrelated physical activities constituting the measuring process as a physical process. The relation between sensible data and their interpretation is essentially the same as those which occur between signal and message in communication theory. This is quite different from that which exists between a physical cause and a physical effect. Cause and effect belong to physics, signal and message belong partly to psychology and partly to the science of communication media. What are usually called observable data appear then in this theory as observable symbols, i.e. symbols of something other than themselves, of electron momenta, of energy levels and other theoretical elements.

Bunge, strongly objectivist in his conception, has attacked the view that physics is about measuring processes by pointing out that physics can truly describe helium atoms in a stationary state even when they are "located beyond the reach of our laboratory ... say somewhere in the Crab Nebula." ${ }^{54}$ In reply, it can be said, in the first place, the stationary states of an atom are determined by the boundary conditions which in turn represent the (averaged) effect of the physical environment with which the helium atom is in contact. In the second place, transitions up from or down to the atom's fundamental state due to the atom's interaction with its environment release photons which travel through cosmic space and which may eventually be recorded and interpreted in an earthly laboratory. The use made of the emitted [410] photon to obtain information about the celestial process makes the photon emission even though it took place lightyears away from the earth part of a measuring process. It is our contention that the meaning of a physical term or variable essentially involves reference to physical processes used as measuring processes.

\section{THEORETICAL MODEL, OBSERVABLE SYMBOL AND REALITY}

The relationship between theoretical model, ${ }^{55}$ observable symbol and reality have to be clarified further.

The scientific method is an empirical method of inquiry of which the aim is to explore the horizon of reality capable of being attained by its own peculiar theoretical-experimental method. It attains its goal, not as Cartesian rationalism taught in the construction or manipulation of theoretical models (however much time in fact the research scientist spends on this aspect of physical research) but in the moment when the existence is recognized through the presentation of sensible data of a real instance of that which a certain theoretical model explains. It is necessary to emphasize that a theoretical model is not a reality. It is an intentional (or ideal) entity. The real scientific entity, however, is not a reified theoretical 
model but an instance of that which the theoretical model explains. The attainment of real instances (the noemata) of the poetic intention is the goal of every noetic-noematic structure. The difference between intentional and real entities has already been touched upon. Each is the object of a different kind of assertion. An intentional entity is the product of a purely noetie intention without a noematic component. A real entity is the goal of a noetic-noematic intentionality-structure. Hence, the real instance for the understanding of which a certain theoretical model is used is not an instance of a real or reified model. The theoretical model is not a referent in the terminal act of scientific inquiry." Its function within [411] the terminal act of scientific inquiry is to render the data significant and intelligible by articulating the structure of the underlying reality. Assertions about reality, then, are not formally assertions about the theoretical model, although they certainly presuppose antecedent (usually mathematical) assertions about the theoretical model..

The foregoing can be illustrated from physics. The theoretical model in physics is always precise as far as its mathematical parameters go to an infinity of decimal places, whether it is a deterministic model (as, in classical physics) or whether it yields merely the form of a statistical distribution (as in quantum physics). The observable data however to which it refers are never precise to an infinity of decimal places, only a certain number of decimal places are significant in any experimental context. The real therefore in physics is never merely a reified instance of a theoretical model but is related to it as a sample is related to a theoretical mean from which it diverges with a certain randomness or indeterminacy. The theoretical model then serves two functions. In the first place, it serves to define by mutual and implicit definition the categories under which the real scientific object is to be subsumed or analyzed. In the second place, it provides an ideal (usually mathematical) law from which the observable data-the symbols under which scientific reality communicates itself-diverge but in a nonsystematic way. The factual is always infected with a certain indeterminacy (relative to any systematic analysis under, which it falls). Whenever then a theoretical model is used to make assertions about factual instances, a (more or less) latent or virtual statistical element enters.58 Individual deviations from the ideal occur at random. These deviations as long as they are non-systematic are judged not to be significant. This does not mean that they are unreal or even small relative to the parameters of the system or to the available instrumentation, but merely that they are devoid of intrinsic intelligibility-as a matter of fact and only in terms of the systematic analysis in question. In a large sample, these deviations cluster around the theoretical model in a manner subject generally (and perhaps surprisingly) to a well-defined statistical distribution. As long as no system can be discerned in these deviations there is no evidence calling for a new and altered systematization on the level of the categorial [412] analysis of the real scientific 
state of affairs. If with more precise measurements, a systematic trend should be discovered in these divergences, then a new theoretical model may be called for. This in turn like its predecessor will do no more than outline another system relative to which factual and real instances will randomly diverge. A virtual statistical element then is always present in the use of theoretical models, even deterministic ones. To quote Max Born:

In classical mechanics the statistical method is used only for systems of very many individual particles. Our model shows that it is obligatory to use it in every case, even that of a single particle in the simplest conceivable circumstances. ${ }^{59}$

A critical realist, therefore, in the style of the present author avoids the two extremes, on the one hand of identifying the real strict object of physical science with sensible data interpreted in common sense terms, and on the other, of identifying it with theoretical models. Sensible data when interpreted within the noetie-noematic structures of common sense reveal of course the common sense realities of the laboratory environment. No one would wish to deny that the pointer position is a real pointer position and the dial a real dial. But, when the noetic-noematic structure of physical science is brought to bear on these common sense events and objects, they take on the character of observable symbols revealing the existence of another horizon, that of scientific reality, the noemata of science. The critical realist on the other hand Also refuses to identify the realistic aim of science with the construction of theoretical models. This latter was the explicit aim of'Cartesian rationalism which many influences, historical, philosophical and not least scientific have to a great measure overthrown. It lingers on however in the minds of phenomenologists who consider erroneously in the present author's opinion that the scientific method is irrevocably and irredeemably tied to Cartesianism.

What then is the terminal object of scientific inquiry? In what does its realistic aspect consist? The terminal object of scientific inquiry is a strict object in the horizon of reality attained by using theoretical models to render intelligible the dynamic pattern of physical interactions between objects of that horizon as manifested in and through the observable symbols produced by the measurement process. Science exercises its realistic function when it uses theoretical models to reveal the interrelatedness of things among themselves.

\section{NOTES}


1 This article was written at the request of the Editor and of some of my students for a non-technical account (avoiding the esoteric language of modern physics) of the epistemological principles used in the author's Quantum Mechanics and Objectivity (Nijhoff: The Hague, 1965). These principles are used to justify a realist interpretation of quantum mechanics. Quantum Mechanics and Objectivity - hereafter referred to as QMO-was written as a doctoral dissertation at the Institut Sup Пrieur de Philosophie of the Catholic University of Louvain, Belgium, under the direction of Professor Jean Ladrière to whom the author owes so much of his philosophical inspiration.

2 See for example Husserl, (1936); Merleau-Ponty 1962); Heidegger (1962). Archives de Philosophie 27 (1964), 323-526 contains the views of a group of phenomenological philosophers about modern science. Representative of their viewpoint is the following statement of R. Boehm: "C'est en effet, surtout le courant phénomenologique qui assume dans la pensé de notre époque la tache polémique de la philosophic vis-à-vis de la science" (p. 425).

3 Husserl's early point of view is in Husserl (1913), Ideen I. His later point of view is to be found in the Husserl (1960).. The part most relevant to the author's method is the Second Meditation, especially sections 19-22 (pp. 44-55 of the English trans.). See note 5 below for the author's personal reservations.

4. Kuhn (1962).

5. Husserl's account of the noetic-noematic polarity of human consciousness is to be found in the Ideen I, especially in sect. 3, chap. 3 (pp. 255-76 of Ideas), and in the Cartesian Meditations, especially in the Second Meditation. Philosophers inspired by Husserl do not always agree with him on the methodological value of certain aspects of his practice of transcendental reduction, e.g. of the epoch $\vartheta$, or of the search for apodicticity, or of the possibility of uncovering a universal a priori in the transcendental subject unconditioned by factual experience. The author's point of view is definitely anti-Husserlian to the extent (i) that he rejects the method of the epoch $\vartheta$, (ii) that he conceives philosophy to be not the search for "absolutely grounded science" but for the a priori conditions of possibility, subjective and objective, of actual (i.e. factual) human experience; (iii) that he believes the universal a priori of the transcendental subject consists not in eidetic essences (these possibly interest the philosopher of esthetic experience) but in the polymorphic structure of human consciousness in which data, understanding of data, and judgement about the understanding of data succeed one another according to certain principles. This point of view is expounded by Lonergan (1957) in which is a study of intentionality-structures though he does not call it that.

5 Dondeyne (1961), pp. 25-26.The present author's point of view more nearly approaches that of Dondeyne than that of Husserl. 
7 de Waelhens (1961), p. 110. For the notion of World in Husserl, see the Ideen I sect. 1, chap. 1 and sect. 2, chap. 1 (pp. 51-52;101-106 in Ideas). "The [environing] World is the totality of objects that can be known through experience, known in terms of orderly theoretical thought on the basis of direct present experience" (p. 52 of Ideas). To appreciate the richness of implication of the term for intentionality-analysis,, read chap. v "Le Monde" of de Waelhens (1961). Since this article was written, the author has read Kockelmans (1966) Phenomenology and Physical Sciences by with great interest. The author remains convinced, however, that phenomenology must be broadened by some analysis of objectivity such as that given by the author in this paper.

8 The author is not using the term 'reality' (or 'optic reality') as a synonym for the traditional term 'being.' By reality, the author means physical reality. Thus, every reality is a being but the possibility remains that the realm of being should turn out to be broader than the realm of reality. Whether or not this is so will depend on the existence and validity of heuristic structures which lead from the real, immanent by definition in the World, to the justifiable affirmation of beings transcendent to the World. The author believes such heuristic structures exist but the course of this inquiry can afford to prescind from them.

9 Husserl calls them cogitatum (qua cogitatum). "Objects (for the transcendental phenomenologist)," he says, "(are solely) the intentional correlates of modes of consciousness of-them." (Cartesian Meds., p. 37.) It does not follow that this inevitably leads to idealism, although it led Husserl in that direction. The nature of strict objectivity as defined below saves the author, he believes, from the closed circle of immanence. The strict object constructed by a man's cognitive activity is only intentionally identified with extra-mental reality, i.e. there is identity (note, not merely isomorphism, as so many writers suppose 1) as to what is meant but not as to being. The assertion 'to be (real)' releases the object-asconstituted by the subject from its dependence on the su ject's act of constitution of the object, thereby acknowledging that the extra mental reality-horizon is not the pure creation of the subject's intentionality. In this way and in this sense, the author escapes hopefully the principle of immanence.

10 'Knowing' is used throughout this article to denote any kind of conscious cognitive activity and not merely justifiable knowledge, still less knowledge of mere sense data.

11 In QMO, the author also used the terms formal objectivity and formal object as synonymous with strict objectivity and strict object. They do not mean what scholastic philosophers mean by formal objectivity and formal object. The scholastic terms are more closely related to what we call the heuristic structure of a horizon than to what we call strict objectivity and strict object. In order to avoid confusion with the scholastic terms, however, the use of the terms formal objectivity and formal object have been dropped in the context of this inquiry. 
12 Lonergan (1957), pp. 250-54 and passim.

13 An interesting book in this connection is Claesges (1964)

14 This is one of the senses used by Husserl. "Objectively valid results'-the phrase after all signifies nothing but results that have been refined by mutual criticism and that now withstand every criticism." (Cartesian Meds., p. 5.) When scientists call science objective, they usually mean intersubjective validity for the competent section of the scientific community; sometimes however the exclusion of all actual relation to human (or instrumental) communities of observers is also implied. The latter extreme interpretation of public objectivity will be considered below.

15 Heisenberg (1952), p. 20. The quotation is from an address delivered in 1934

16 See W. Heisenberg in Pauli (1955), pp. 25ff.

17 Lonergan uses the term 'absolute objectivity' to express the severing of the ties between the constituted object and the subject's act

18 I suppose what the vast majority of physicists take for granted in practice, namely, that physics intends to discover and express what really is, though in any particular case or with any particular theory they realize that it may be in error.

19 It seems that the verb 'to be' belongs to every language. In its strong meaning of to exist (as a reality-for a subject) or to be real (for a subject), it specifies the ultimate all-englobing horizon, the "horizon of all horizons," which unifies all, the particular horizons of reality and makes them to be no more than aspects of one Reality -- the World-for-subject

20 Cf. Lonergan (1957), pp. 375-77.

21 I do not mean to exclude the possibility-much less the fact-that sense data enter awareness in an already highly elaborated form, synthesized into Gestalten of many kinds. The Gestalten are given with the sense data. They are not usually however what is meant by an ordinary cognitive act influenced by sense data and intending reality. The Gestalten are the appearances or symbols of reality or channels of communication modulated by the presence of reality. That which they reveal depends on the interpretation of the Gestalten and this in turn is a function of the culture, age, profession and history of the interpreter. On the interpretation of the Gestalten of sense experience, see Abraham Moles,(1966) , or James J. Gibson, The Senses as Perceptual Systems (Boston: Houghton Miflin, 1966).

22 Cf. Wilfrid Sellars, "Empiricism and the Philosophy of Mind," Minnesota Studies in the Philosophy of Science, vol. 1 (Univ. of Minnesota Press, 1965), pp. 253-329.

23 Psychophysical parallelism originating with G. Th. Fechner in the last century came to influence the epistemological interpretation of physics through the works of Wilhelm Ostwald. It was used by N. Bohr and J. von Neumann in the explanation of the observer-problem-the so-called 'reduction of the wave 
packet'-in quantum mechanics. See for instance, Bohr's Atomic Theory and the Description of Nature (Cambridge Univ. Press, 1934), pp. 102-19 and J. von Neumann's Mathematical Foundations of Quantum Mechanics, trans. by R.Y. Beyer (Princeton Univ. Press, 1955), p. 420. See K. Popper's refutation of psychophysical parallelism in Conjectures and Refutations (London: Routledge and Kegan Paul, 1963), p. 295.

24 Between the author's use and Husserl's use of the terms noetic-noematic, horizon and World there are some fundamental differences. These spring from the rejection of the method of the epoché. To bracket existence is, the author believes, to frustrate the possibility of ever understanding the nature of human cognitive intentionality. Every human cognitive intention is a, movement beyond the eidetic synthesis of sense impressions towards an object to be asserted (a strict object). The eidos plays a preliminary role in preparing the appearance (or phenomenon) or symbol or channel of communication relative to the strict object. Husserl would limit a horizon or the World to objects "given primordially in perception"that is, to those which are subject to an eidetic synthesis and no more. The author proposes to have horizons (and ultimately the World-for-subject) constituted out of objects synthesized by the affirmation 'to be (real).' This provides a single universal all-englobing horizon of reality, the World. The set of strict objects corresponding to valid empirical procedures is then unified at the subjective pole by the transcendental Ego and at the objective pole by this ultimate horizon, the World-for-subject.

25 An alternative formulation of the same position is that meaning (of a term or sentence) is always relative to a language. expressed in this way, the position agrees with one of the central theses of W. Sellars, Carnap and many logical empiricists. The relation between language and intention is studied below.

26 For a discussion of 'black box' theories of science, see Mario Bunge's interesting article "Phenomenological Theories" in The Critical Approach to Science and Philosophy: Essays in Honor of Karl R. Popper, ed., by M. Bunge (New York: Free Press, 1964), pp. 234-54.

27 Another term for "ideal relational norm" is a (conceptual) Gestalt.

28 Cf. QMO, pp. 57-61 and passim.

29 For instance,. N. Bohr, Atomic Theory and the Description of Nature (Cambr. Univ. Press, 1961). pp. 1, 5, 8, 17, 53, and W. Heisenberg, Philosophic Problems of Nuclear Science (London: Faber and Faber, 1952), p. 45 and Physics and Philosophy (New York: Harper, 1958), pp. 44, 144. Cf. QMO, chaps. iii and viii.

30 Cf. QMO, pp. 57-61, $176 f f$

$31 \mathrm{Cf}$. ibid., chap: iv and passim.

32 Cf. ibid., chap. ix.

33 Cf. ibid., pp. 59-60, 175-79. 
34 On the forms of correspondence rules, see E. Nagel, The Structure of Science (London: Routledge and Kegan Paul, 1961), pp. 93-105, and A. Pap, Introduction to the Philosophy of Science (London: Eyre and Spottiswoode, 1961), chaps. i-iv.

35 An interesting account of the multiplicity of levels of meaning found in esthetic experience is given in Information Theory and Esthetic Perception, trans. by Joel E. Cohen (Univ. of Illinois Press, 1966).

36 Is this what W. Sellars means when he says of correspondence rules, "Can they not be regarded as statements to the effect that certain redefinitions of observation terms would be in principle acceptable. This would be compatible with the fact that the redefinitions in question are implemented only in the syntactical dimension, no theoretical expressions actually acquiring the observational-perceptual roles they would have to have if they were to be synonyms of other expressions playing this role"? Current Issues in the Philosophy of Science, ed. by H. Feigl and G. Maxwell (New York: Holt, Rinehart, Winston, 1961), p. 76.

37 Cf. QMO, pp. 31, 107, and passim.

38 The set $\left\{\mathrm{Q}_{0}(\mathrm{x})\right\}$ designates the range of discernably different events (or observable symbols). If $\mathrm{x}$ is a continuous numerical variable, the range of $\mathrm{x}$ must be broken up into intervals not smaller than the threshold of resolution below which the consecutive events designated by $\mathrm{Q}_{0}$ (a) and $\mathrm{Q}_{0}\left(\mathrm{x}_{\mathrm{a}}+1\right)$ merge in perception. The set $\left\{\mathrm{R}_{\mathrm{i}}(\mathrm{y})\right\}$ designates the range of scientific events or states in one-to-one correspondence with the set $\left\{\mathrm{Q}_{0}(\mathrm{x})\right\}$.

39 Note that this is not a behaviorist theory of meaning in the 'reductionist' sense. Meaning is not behavior: but meaning is related to behavior as that which we attain as objects of cognition through the kind of physical behavior in question. The mode of heuristic behavior (internal or external) specifies a channel of communication through which we receive messages about a horizon of meant objects.

40 See any work of the sociology of knowledge, for example, The Sociology of Knowledge by Werner Stark (Free Press, 1958), or Thomas Kuhn, The Structure of Scientific Revolutions.

${ }^{41}$ Logic of Modern Physics (Macmillan, 1928), pp. 1-25. A. Pap's incisive criticism of operationalism is worth noting. It is in chaps. i-iv of his Introduction to the Philosophy of Science. See also the criticism of M. Bunge in Brit. Jour. Phil. Science, 9 (1958), 76-77.

42 In H. Margenau, "Measurement and Quantum States," Philosophy of Science, 30 (1963), 138-57, it is stated that a physical act of measurement must obey the following three criteria: "a) it is a special kind of interaction 'entangling' the system under observation with an apparatus, b) it must yield numbers, c) the numbers refer to states of affairs before the interaction" (p. 142). 
43 H. Margenau, ibid., J. von Neumann, Mathematical Foundations of Quantum Mechanics (Princeton Univ. Press, 1955). E. Wigner seems to agree with von Neumann; cf. his "Problem of Measurement," Amer. Jour. Phys., 3 (1963), 6ff.

${ }^{44}$ Heisenberg's own account of this insight is contained in "Erinnerungen an die Zeit der Entwicklung der Quantenmechanik," in Theoretical Physics in the Twentieth Century; A Memorial Volume to Wolfgang Pauli, ed. by M. Fierz and J. F. Weisskopf (New York: Interscience, 1960), pp. 40-47.

45 This follows from the fact that the conditions of an experiment enter into the definition of any phenomenon to which the term 'physical reality' can be properly applied. Since certain conditions are incompatible with others, the performance of these conditions-even if they do not physically interfere with the system-allows us to call real a property which was not real before. The argument is abstracted from Bohr's "Discussion with Einstein" in Albert Einstein: Philosopher-Scientist, ed. by P. A. Schilpp (Library of Living Philosophers, 1949).

46 Cf. QMO, pp. 64-66.

47 For Newton, the ideal of science was to "see" what God "saw." This is described in the following passage from the Opticks: ".., there is a Being incorporeal, living, intelligent, omnipresent who in infinite space, as it were in his sensory, sees things themselves intimately ... of which things the images only [i.e., on the retinal carried through the organs of sense into our little sensoriums are there seen and beheld by that which in us perceives and thinks." Opticks (3rd ed., London 1721), p. 344. The passage is cited in Metaphysical Foundations of Modern Physical Science, by E. A. Burtt (Routledge and Kegan Paul, 2nd ed. 1931), p. 258.

48 Objectivism, characteristic of the Newtonian and Cartesian mentality, has come to be regarded by contemporary philosophers of the phenomenological tradition as one of the most baneful and inevitable consequences of the scientific outlook. See note 2 above.

49 The author rejects the phenomenological thesis that objectivism is an inevitable consequence of the scientific outlook. A proper understanding of the scientific enterprise involves a reflexive return to the subjectivity of the human knower. The Cartesian objectivism of classical physics is bad physics as well as had philosophy. Most phenomenologists demand that genuine scientific knowledge relate the object directly in some way to the subject; that is, as a thingto-subject-for-subject. The position that scientific horizons are horizons of thingto-instrument-for-subject is intermediate between Cartesian objectivism and the extreme of phenomenological subjectivism.

50 See note 47 above. 
51 N. Bohr, Atomic Theory and the Description of Nature, pp. 11, 54, 68, 93, 115 etc.; W. Heisenberg, The Physical Principles of Quantum Theory (Univ. of Chicago Press, 1930).

52 Cf. N. Bohr's "Discussion with Einstein on Epistemological Problems in Atomic Physics" in Albert Einstein: Philosopher-Scientist, ed. by P. A. Schilpp (Library of Living Philosophers, 1949) ; J. von Neumann, Mathematical Foundations of Quantum Mechanics. The difference between Bohr and von Neumann is in the treatment of the macroscopic measuring apparatus. Bohr by describing it classically left the object-instrument interaction unexplained. Von Neumann removed this anomaly by subjecting the macroscopic instrument also to quantum mechanical treatment. An excellent account of this matter is to be found in.P.K. Feyerabend's "Problems of Microphysies" in Frontiers of Physics and Philosophy, ed. by R. G. Colodny (Univ. of Pittsburgh Press, 1962).

53 Cf. QMO, chap. vi.

54 M. Bunge, "Physics and Reality," Dialectica, 10 (1965), 204

55 The theoretical model is the appropriate solution of the mathematical equations when the boundary conditions have been assigned, taken with the physical interpretation which belongs to the formalism as a physical theory. By 'model' the author does not mean a mechanical or visualizable analogue of the physical reality subject to similar mathematical laws.

56 Bunge holds a contrary view (as far as I can judge). He writes: "Referentially (semantically) considered a physical theory points in an immediate way to a conceptual model which is in turn supposed to symbolize a real system of some kind. Just as the immediate referent is a construct, so the mediate referent can in fact be nonexistent' and in any case it need not be observable." Dialectica, 19 (1965), 211. The last phrase bears a resemblance to the author's position, but the epistemological context is quite different.

57 Hence, realistic assertions have empirical content and are subject to (empirical) confirmability in principle.

58 Cf. QMO, pp. 18-19, 38-41, 101-109, passim.

59 M. Born "Is classical mechanics in fact deterministic?" reprinted in Physics in My Generation, by Max Born (London: Pergamon Press, 1956), p. 168. Cf. also QMO, chap. vi. 